Check for updates

The BMJ

Cite this as: BMJ2020;370:m3579 http://dx.doi.org/10.1136/bmj.m3579 Published: 14 September 2020

\section{Covid-19: Implication GPs haven't seen patients in person is an insult, says RCGP}

Abi Rimmer

The Royal College of GPs has said that a letter from NHS England calling on GP practices to ensure that they offered face-to-face consultations is an insult.

The letter was sent to all practices in England and was accompanied by a communications toolkit designed to signpost the availability of face-to-face consultations to patients.

It said that some patients had reported difficulty in accessing their GP for face-to-face appointments. "We are writing to reiterate the importance of providing face-to-face appointments for those who need them and to share materials designed to support your clear communication with patients about how they can access the right type of appointment for them," the letter from NHS England said.

In response, RCGP chair Martin Marshall said that practices had been open throughout the pandemic, delivering a predominantly remote service to comply with guidance and help stop the spread of covid-19. ${ }^{1}$

“Any implication that they haven't been doing their job properly is an insult to GPs and their teams who have worked throughout the pandemic, continued delivering the vast majority of patient care in the NHS, and face an incredibly difficult winter ahead," Marshall said. "As well as delivering routine care to patients with both covid-19 and non-covid-19 conditions, GPs have been working in 'hot hubs,' identifying those at most risk from the virus and advising them on how to stay safe, and supporting NHS 111 and other areas."

NHS England said that between March and July NHS Digital estimated that there were 102 million appointments in general practice, half of which were over the phone or through video calls.

Marshall said that while remote consultations would suit some patients better than others, most had understood the rationale for them. He said that the RCGP did not want to see general practice become a totally, or even mostly, remote service post-pandemic. "We are, however, still in the middle of a pandemic. We need to consider infection control and limit footfall in GP surgeries-all in line with NHS England's current guidance."

Graham Jackson, chair NHS Clinical Commissioners, said that the vast majority of GP practices had continued to offer face-to-face consultations where clinically appropriate throughout the pandemic. "We should not lose sight of the significant benefits provided by telephone and video consultations and we need to maintain a good balance between face-to-face appointments and remote consultations," he said. "Patients' best interests must be served, this includes protecting them from unnecessary exposure to infection."

Medical director of primary care for NHS England Nikki Kanani said that general practice had played a vital role in the fight against coronavirus, adapting quickly to significantly increase the availability of video and phone consultations and offer safe face-to-face care when needed. "While many people, particularly those most vulnerable to covid-19, want the convenience of a phone or video consultation, the NHS will continue to offer face-to-face appointments and I would urge anyone who feels they need medical support to come forward so they can get the care, support, and advice they need. The NHS is here for you," she said.

RCGP. "Insult" to GPs to imply they haven’t been doing their job properly during pandemic, says RCGP. 14 September 2020. www.rcgp.org.uk/aboutus/news/2020/september/insult-to-gps-to-imply-they-havent-been-doing-their-job-properly-during-pandemic.aspx. 